\section{$\underset{\substack{\text { hommes } \\ \text { \& migrations }}}{ }$}

Hommes \& migrations

Revue française de référence sur les dynamiques

migratoires

1302 | 2013

Le Japon, pays d'immigration?

\title{
Étudiants étrangers et travailleurs qualifiés au Japon
}

\author{
Hélène Le Bail
}

\section{(2) OpenEdition \\ Journals}

\section{Édition électronique}

URL : http://journals.openedition.org/hommesmigrations/2478

DOI : 10.4000/hommesmigrations. 2478

ISSN : 2262-3353

\section{Éditeur}

Musée national de l'histoire de l'immigration

\section{Édition imprimée}

Date de publication : 1 avril 2013

Pagination : $42-43$

ISBN : 978-2-919040-22-3

ISSN : $1142-852 X$

\section{Référence électronique}

Hélène Le Bail, «Étudiants étrangers et travailleurs qualifiés au Japon », Hommes \& migrations [En ligne], 1302 | 2013, mis en ligne le 31 décembre 2015, consulté le 02 mai 2019. URL : http:// journals.openedition.org/hommesmigrations/2478; DOI : 10.4000/hommesmigrations.2478 


\section{ÉTUDIANTS ÉTRANGERS ET TRAVAILLEURS QUALIFIÉS AU JAPON}

par HÉLÈNE LE BAIL, chercheur en science politique, Maison franco-japonaise, UMIFRE 19 CNRS-MAEE

\section{Mise au jour d'un processus d'installation depuis deux décennies}

Le Japon affiche officiellement une politique d'immigration restreinte et privilégiant les travailleurs les plus qualifiés. Ainsi, la réforme de la loi de contrôle de l'immigration et de reconnaissance du droit d’asile de 1989 (entrée en vigueur en 1990) a déterminé 13 catégories de visas dits de "travail qualifié", tels ceux de professeur, chercheur, ingénieur, journaliste, spécialiste des ressources humaines et des affaires internationales, mais aussi le visa très polémique du "monde du spectacle", avec lequel beaucoup de femmes asiatiques sont venues travailler dans les bars.

En 2010, les résidents en possession d'un des 13 visas de travail qualifié représentaient $9 \%$ des résidents étrangers. Si l'on privilégie une définition des travailleurs hautement qualifiés plus proche de celle de l'OCDE, leur nombre serait encore moins important. Les politiques devant promouvoir l'entrée des travailleurs les plus qualifiés sont donc considérées comme très insuffisantes ${ }^{1}$. Le gouvernement a récemment mis en place un système à points qui propose aux plus qualifiés des conditions de résidence privilégiées (non-restriction du secteur d'activité, permis de résident permanent après cinq ans de résidence, possibilité pour les conjoints de travailler à temps plein, possibilité de faire venir les parents, possibilité d'employer du personnel de maison étranger).

Toutefois, jusqu'à aujourd'hui, la meilleure façon d'attirer des travailleurs étrangers hautement qualifiés et efficaces sur le marché japonais reste la promotion des études supérieures ${ }^{2}$. Or le nombre d'étudiants étrangers dans les universités japonaises est inférieur à celui de la plupart des pays riches, tels la France ou l'Allemagne, sans parler des pays anglophones. Dans la continuité d'une première grande politique Objectif 100000 étudiants étrangers lancée en 1984, le gouvernement a annoncé en 2008 l'Objectif 300000 étudiants étrangers, qui vise à faire passer le nombre d'étudiants internationaux de 140000 à 300000 d'ici 2020³. Pour soutenir cette politique, a été créé le projet Global 30 qui assure un soutien financier d'ampleur dans les plus grandes universités publiques et privées 


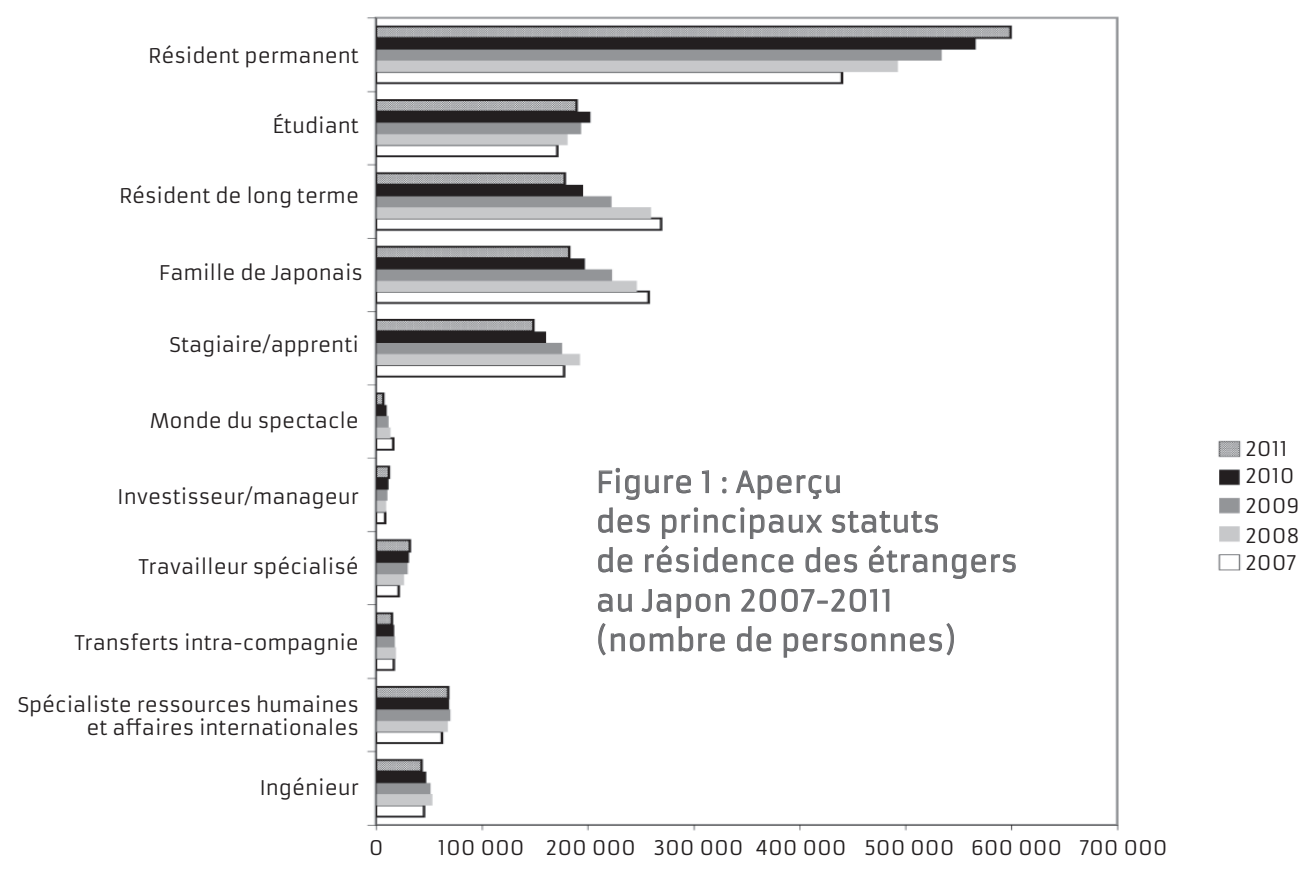

Source : à partir des statistiques du ministère de la Justice, 2012.

pour qu'elles mettent en place des structures et des formations destinées aux étudiants étrangers.

Malgré les difficultés du Japon pour attirer travailleurs qualifiés et étudiants, et malgré la réticence du gouvernement à afficher officiellement une politique d'immigration, un processus d'installation des travailleurs s'opère depuis maintenant plus de deux décennies. Les rangs des résidents permanents (figure 1), plus de 590000 en 2011, sont en grande partie composés d'anciens étudiants ayant obtenu un permis de travail à l'issue de leurs études, puis le statut de résident permanent, en moyenne au bout de cinq ans de travail qualifié au Japon. Les résidents chinois (plus de 180000 résidents permanents en 2010) sont les principaux concernés par ce processus d'intégration sur le marché du travail qualifié ${ }^{4}$. Ils représentent environ les deux tiers des étudiants étrangers au Japon, ainsi que les deux tiers des visas de travail accordés à la fin des études. Ils représentent aussi plus de la moitié des travailleurs possédant un visa d'ingénieur ou de spécialiste en ressources humaines et affaires internationales. Contrairement à d'autres groupes de résidents étrangers (les descendants de Japonais d'Amérique latine ou les épouses asiatiques, par exemple), le nombre d'étudiants, de travailleurs qualifiés et de résidents permanents chinois est resté stable, voire a continué de croître après la crise financière de 2008 (l'impact de la crise écologique de 2011 est encore incertain). Cela semble confirmer un processus de mobilité sociale professionnelle favorisant leur intégration, en partie grâce au dynamisme de l'économie transnationale sinojaponaise qui leur offre une niche d'activité . $^{\text {. }}$ 